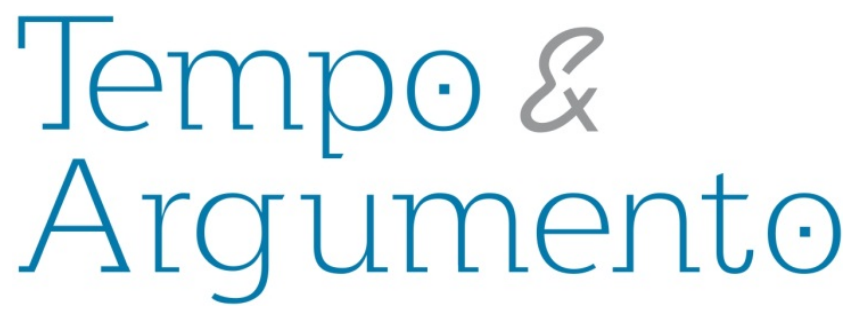

\title{
"Se mataban entre ellos." El rumor y la desconfianza: dos armas en la contrainsurgencia del México de los años 1970
}

\begin{abstract}
Resumen
Este artículo aborda el fenómeno insurgente y contrainsurgente del México de los años 1970 desde el estudio del "rumor" y la "desconfianza" como estrategias de desarticulación de organizaciones insurgentes. Se sustenta metodológicamente en la triangulación de entrevistas a militantes, archivos hemerográficos y documentos oficiales de la Dirección Federal de Seguridad (DFS). También traza de forma general la vinculación de los militantes que compusieron la generación fundadora de la Liga Comunista 23 de Septiembre en el norte del país y analiza el carácter de las acciones de violencia política más recurrentes en sus primeros años de existencia. Por último, reflexiona sobre los procesos de represión política en la década estudiada.
\end{abstract}

Palabras clave: Liga Comunista 23 de Septiembre; Organización Insurgente; Contrainsurgencia; Represión política; Violencia Política.

\author{
Alicia de los Ríos Merino \\ Profesora Doctora e investigadora de la Escuela \\ Nacional de Antropología e Historia del Instituto \\ Nacional de Antropología e Historia \\ (ENAH/INAH), Chihuahua, \\ México. \\ litxadelosrios@hotmail.com
}

\section{Para citar este artículo:}

RÍOS MERINO, Alicia de los. "Se mataban entre ellos." El rumor y la desconfianza: dos armas en la contrainsurgencia del México de los años 1970. Florianópolis, v. 7, n.16, p. 129 - 153. set./dez. 2015. 


\section{"They killed each other."} Rumor and distrust: two weapons in Mexico's counterinsurgency in the $1970 \mathrm{~s}$

\begin{abstract}
This article addresses Mexico's insurgency and counterinsurgency phenomenon in the 1970 s by analyzing "rumor" and "distrust" as strategies for dismantling insurgent organizations. It is methodologically based on triangulation of interviews with militants, hemerographic files, and official documents of the Mexican Federal Security Direction (DFS). It also generally outlines the links between militants who made up the founding generation of Liga Comunista 23 de Septiembre in northern Mexico and analyzes the nature of the more recurrent political violence actions in its early years. Last, it thinks through the political repression procedures in the decade under study.
\end{abstract}

Keywords: Liga Comunista 23 de Septiembre; Insurgent Organization; Counterinsurgenc; Political Repression; Political Violence.

\section{"Matavam uns aos outros." O rumor e a desconfiança: duas armas na contrainsurgência do México dos anos 1970}

\begin{abstract}
Resumo
Este artigo aborda o fenômeno insurgente e contrainsurgente do México dos anos 1970 tomando por base o estudo do "rumor" e da "desconfiança" como estratégias de desarticulação de organizações insurgentes. Apoia-se metodologicamente na triangulação de entrevistas com militantes, arquivos hemerográficos e documentos oficiais da Direção Federal de Segurança (DFS), do México. Traça, também, de modo geral, a vinculação dos militantes que compuseram a geração fundadora da Liga Comunista 23 de Septiembre no norte do país e analisa o caráter das ações de violência política mais recorrentes em seus primeiros anos de existência. Por fim, reflete sobre os processos de repressão política na década em estudo.
\end{abstract}

Palavras-chave: Liga Comunista 23 de Septiembre; Organização Insurgente; Contrainsurgência; Repressão Política; Violência Política. 
Los años 1970 son un periodo de inflexión en la sofisticación de las estrategias contrainsurgentes en México. Los organismos de seguridad, en cabeza de la Dirección Federal de Seguridad (DFS), diseñaron una serie de mecanismos que fomentaban la desconfianza y el rumor dentro de las organizaciones políticas opositoras. Con el objetivo de comprender estas estrategias, este artículo estudia el accionar colectivo de los militantes de la Liga Comunista 23 de Septiembre, en un escenario predominantemente urbano, y presta especial atención a las prácticas más recurrentes de violencia política de esta organización en la década, además de la orientación de aquellas acciones sobre sectores de población específicos.

Se analizan cómo fueron interpretadas estas acciones por la opinión pública, los organismos de seguridad y las elites políticas y económicas del norte de México. Así mismo, se caracterizan los sujetos que conformaron el núcleo fundador de la Liga en el norte del país, se perfilan sus procesos de vinculación a la organización y sus primeras y más comunes formas de interacción con las Fuerzas Armadas del Estado. A continuación, me concentro en el rumor y la desconfianza como armas de disgregación de la insurgencia y recurso principal para la tortura física y psicológica de los presos políticos. Por último, se presentan las conclusiones, donde se exponen algunas reflexiones generales sobre los procesos de represión política de la contrainsurgencia mexicana.

\section{La retención como práctica recurrente de violencia política}

Entre las prácticas de violencia política que despliegan las organizaciones insurgentes ${ }^{1}$, el secuestro de empresarios, políticos y diplomáticos fue una práctica

\footnotetext{
${ }^{1}$ Retomo la categoría organización insurgente que proponen los historiadores Jorge Holguín y Miguel Reyes en La Insurgencia urbana en Colombia: accionar colectivo del M-19 en Cali, 1974-1985 (en prensa), para caracterizar el accionar colectivo de la Liga Comunista 23 de Septiembre en México. Los autores hacen un uso restrictivo del término "guerrilla", el cual consideran: "una categoría fundamentalmente descriptiva de una forma de acción colectiva especifica dentro de un repertorio más amplio de violencia política". Esto permite avanzar en la comprensión integral de las acciones colectivas armadas y no armadas de estas organizaciones, que van desde acciones ofensivas, como ataques militares a la fuerza pública y secuestros de personas acaudaladas, hasta trabajos no militares orientados al interior y exterior de sus estructuras, como la politización y radicalización de sectores de población potencialmente revolucionarios, con el propósito de avanzar a la toma del poder del Estado. Presenté una primera versión de este texto en el II Coloquio de Movimientos Sociales, Dirección de Estudios Históricos, Instituto Nacional de Antropología e Historia (INAH), noviembre de 2014; agradezco
} 
común en los años 1970. Por ejemplo, el 5 de mayo de 1973 en Guadalajara, Jal., un comando de las Fuerzas Armadas Revolucionarias del Pueblo (FARP) secuestró a Terrance Leonhardy, cónsul norteamericano en esta ciudad. Después de ceder a las demandas del FARP, el gobierno mexicano pagó 4 millones de pesos y facilitó el traslado de una treintena de presos políticos hacia Cuba. El cónsul fue liberado dos días después.

Tras este éxito, militantes de la recién constituida Liga Comunista 23 de Septiembre $(\mathrm{LC} 23 \mathrm{~S})^{2}$, específicamente aquellos que provenían del grupo conocido como “Los Macías” del noreste mexicano, sugirieron al interior de su organización el secuestro de Eugenio Garza Sada, presidente del Consorcio Industrial Cervecería del Grupo Monterrey. En esta primera reunión fundacional, tomaron una serie de decisiones para hostigar política y militarmente al Estado mexicano y a la burguesía. Entre las acciones destinadas para este fin, destaca el secuestro de personajes que idealmente serían canjeados por dinero y presos políticos.

Uno de los elegidos fue el regiomontano Eugenio Garza Sada. Este empresario nació el 11 de enero de 1892, en la ciudad de Monterrey, una de las más industrializadas del país. Era el segundo hijo de una familia que se exilió en los Estados Unidos al inicio del conflicto armado revolucionario de 1910. Realizó estudios de ingeniero en el Instituto Tecnológico de Massachusetts (MIT) para regresar en 1917 a laborar en la Cervecería Cuauhtémoc, empresa de la cual su padre era accionista y que décadas después se convertiría en la empresa madre de un complejo de empresas pertenecientes a la misma familia Garza.

Precursor e ideólogo del progreso en el norte de México, creó la sociedad civil “Enseñanza e Investigación Superior” (EISAC), que posteriormente se transformaría en el Instituto Tecnológico y de Estudios Superiores de Monterrey (ITESM). Patrocinador tanto de equipos de béisbol de la Cruz Roja, de bomberos y de estudiantes regios, se convirtió

a Eduardo Flores Clair por motivar la existencia de este texto, así como a Gerardo Necoechea y a Jorge Albeiro Holguín por las observaciones, sugerencias y la lectura constante.

${ }^{2}$ La LC23S se fundó formalmente el 15 de marzo de 1973, cuando en Guadalajara se reunieron de manera clandestina representantes de aproximadamente una decena de grupos político-armados para fundar esta organización nacional. Existía entre ellos consenso sobre el fin principal de su actividad política: instaurar el socialismo a través de la lucha armada y la construcción de un partido del proletariado. Todos eran jóvenes de menos de 30 años de edad. La mayoría varones y pertenecían a pequeños grupos de distintas ciudades del país, principalmente de la región norte y el Distrito Federal. 
Los Integrantes de la Liga que prepararon la acción planearon exigir un rescate de 5 millones de pesos y la liberación de un grupo de prisioneros políticos. La mañana del 17 de septiembre de 1973, un comando con seis jóvenes intentó secuestrar a Garza Sada cuando éste se dirigía a sus oficinas. El operativo se salió de control al desatarse una balacera entre el guardaespaldas del empresario y los militantes. En fuego cruzado, murieron Garza Sada -de entonces 81 años-, su guardaespaldas y el chófer, así como Anselmo Herrera Chávez y Javier Rodríguez Torres, integrantes de la Liga.

La condena hacia esta organización insurgente no se hizo esperar. Decenas de miles acudieron a sus exequias. El grupo industrial de Monterrey, la Iglesia y los políticos exigieron al entonces presidente Luis Echeverría Álvarez una actuación rápida en contra de los responsables, acusando a su gobierno de no tener mano dura con "los fanáticos radicales”. El periódico nacional La Prensa caracterizó a los responsables del homicidio del empresario como "fanáticos enajenados [... ] minoría de eternos inconformes que todo lo quieren resolver por la violencia, incapacitados como están para usar la razón" (GAMIÑO, 2011, 108-109). ${ }^{4}$ En la misma nota se sugirió a las autoridades castigar de forma ejemplar mediante sentencias judiciales.

No obstante, llama la atención que a lo largo de las investigaciones no se publicitó la existencia de la LC23S como una organización opositora al régimen. Para Gamiño, la omisión tenía un propósito principal:

[...] simular tener un desconocimiento del fenómeno armado. La estrategia consistió en negar la existencia de una nueva organización que operaba a nivel nacional y que logró amalgamar a diversos grupos desarticulados. El desconocimiento y negación tuvo dos objetivos: reducir la capacidad operativa de la organización y apologizar la

\footnotetext{
${ }^{3}$ Se consultaron diversos textos biográficos, basándonos para este artículo en la información en línea del ITESM: http://www.pegs.com.mx/semblanza.htm, consultada el 20 de mayo de 2015.

${ }^{4}$ Gamiño retoma una nota del diario La Prensa, del 19 de septiembre de 1973, así como una columna de opinión titulada "Editoriales", sin autor, del día siguiente.
} 
Ante esta demanda de castigos ejemplares, la investigación policiaca -difundida públicamente desde la prensa-, señaló como responsables a algunos integrantes de un grupo radical asociado a la Liga Comunista Espartaco y conformado en 1967 por Mónico Rentería y Salvador Corral. En esta fabricación de culpables, hubo una excepción: la detención de Elías Orozco Salazar, participe en el intento de secuestro, y cuya captura se dio el 6 de octubre en el parque Popo Park, sitio cercano a la Ciudad de México, en hechos que aparentemente no guardaban relación con las pesquisas del caso Garza Sada. ${ }^{5}$ Diez días después, Mónico fue detenido por agentes de la policía judicial federal en una localidad de Durango, acusado de ser el autor intelectual del secuestro y homicidio de Garza Sada. Aún con la certidumbre de que una mayoría de los acusados no participaron en el intento de secuestro, se les envió a la cárcel.

\section{Los Macías antes y después de la LC23S}

Salvador Corral García y Mónico Rentería Medina se conocieron en la Ciudad de México, en 1967. Salvador estudiaba en la Universidad Nacional Autónoma de México el segundo año de medicina, y Mónico era profesor de primaria. Hicieron parte de movilizaciones populares y organizaciones políticas y se inspiraron en la teoría del foco guerrillero cubano para conformar un grupo revolucionario. Un año después, se les unirían Edmundo Medina Flores; los tres eran oriundos del norte del país. En un principio, el grupo no tenía nombre, aunque se les identificó posteriormente como “Los Macías". Luego vendrían divisiones.

\footnotetext{
${ }^{5}$ Los comités militares de la LC23S se encontraban reunidos en el campamento Popo Park, en el estado de México. La reunión fue descubierta el 5 de octubre de 1973, logrando escapar algunos y quedando detenidos otros. En el enfrentamiento, murió el encargado de seguridad de la reunión, Alfonso Rosas, alias "Arturo". La llegada de los cuerpos policiacos a la reunión ocasionó una serie de acusaciones, señalamientos y desconfianzas entre los asistentes que pertenecían a diversos grupos estatales o regionales.
} 
En 1970, Salvador conoció a Elías Orozco Salazar, ingeniero agrónomo e integrante de un grupo guerrillero que actuaba en Monterrey. Dicho grupo realizó un robo a las oficinas de General Electric. Corral García declaró no haber participado en esta acción, pero recibió 60 mil pesos, de los cuales entregó la mitad a Mónico. Después del asalto a la planta de General Electric en Monterrey, Los Macías subieron de nuevo a la región serrana de Durango, donde decidieron expulsar a Mónico del grupo que él mismo había conformado, por diferencias que entonces parecieran irreconciliables.

Edmundo asumió la dirección del grupo. Mónico se instaló en la región de la Comarca Lagunera para dedicarse a la docencia y la gestión entre los campesinos, mientras que Salvador y Edmundo fortalecieron las relaciones con los jóvenes de Monterrey, quienes actuaban en una coordinación conocida como La Partidaria, antecedente de la LC23S. Salvador declaró que en 1972 y parte de 1973 vivió en las ciudades de Monterrey, Chihuahua y Durango, reclutando y politizando a nuevos miembros para la organización.

Según testimonios de sobrevivientes, Salvador Corral no formó parte del comando que intentó secuestrar a Garza Sada. Sólo un expediente de la DFS registra una referencia a Juan Corral como participante en el homicidio del empresario norteño. En un recorte de periódico que guarda la familia de Salvador se observa un cartel con la leyenda "Prófugos de la justicia". Aparecen las fotos de los militantes de la LC23S: Salvador Corral García, Miguel Ángel Torres Enríquez, Maximiano Madrigal Quintanilla, Edmundo Medina Flores e Hilario Juárez García, todos señalados como presuntos responsables del triple homicidio. Las autoridades alertaban a la población: "Precaución, peligrosos y armados. Modifican su apariencia con barba y bigote. Cualquier informe debe de ser proporcionado a las autoridades locales, estatales, federales a la dirección de la policía judicial de Nuevo León”. Dicha publicación coincide con la correspondencia de Luis de la Barreda Moreno, director de la DFS, a un inspector general de policía:

Envía fotos de Edmundo Medina Flores (a) Ricardo y de Salvador Corral García (a) Juan Corral o Roberto, solicitando cooperación para su detención, ya que se encuentran relacionados con la tentativa de secuestro y homicidio del señor Eugenio Garza Sada y sus acompañantes. Se trata de individuos altamente peligrosos (DIREÇÃO, 1973. ). 
Las repercusiones del fallido secuestro alcanzaron Ciudad Juárez. Rigoberto Ávila fue alumno del Instituto Tecnológico Regional de Ciudad Juárez, en donde participó como huelguista en la primavera de 1972. Invitado por Luis Miguel Corral a la Liga Comunista 23 de Septiembre, fue uno de sus precursores en la frontera. Rigoberto recuerda que durante ese proceso fundacional,

[...] lo que nos trastocó mucho el ritmo que ya llevábamos fue lo de Garza Sada, de ahí para adelante ¡Pum! Como que todos los tiempos, todo se alteró, totalmente se alteró y luego la caída ahí en la casa (de los Corral) pues complicó las cosas, ya no llegamos, jamás volvimos. (RIGOBERTO, 2009)

Rigoberto se refiere al cateo en la casa de los Corral García (entrevista a Rigoberto Ávila, 7 de noviembre de 2009).

El 17 de octubre, un día después de que la policía judicial de Nuevo León detuviera a Mónico Rentería, Ilegaron a Ciudad Juárez buscando a Salvador. Luis Miguel, desde la clandestinidad en la misma ciudad fronteriza, advirtió a su hermano Roberto de que lo iban a detener (Salvador en la clandestinidad se hacía llamar "Roberto"). Le pidió regresar a casa y deshacerse de libros, fotografías familiares, cartas. No le dio tiempo. Aproximadamente quince policías judiciales de Monterrey y elementos de la DFS arribaron a eso de las dos de la tarde y se lo llevaron detenido al primer batallón de infantería de Juárez. Él recuerda que lo amenazaban: "si no proporcionas información sobre Salvador te vamos a echar al mar, y a toda tu familia la vamos a ir a matar ahorita mismo”. Él mismo se cuestiona: “¿Es tortura, verdad? no de golpes, pero también duele”. Lo que le preocupaba era que lo hicieran hablar sobre aquello que conocía, sus hermanos militantes. Por ello dice que era repetitivo en lo que contestaba. Le presentaron fotografías en las que sólo reconoció a Mónico Rentería. Después de 24 horas lo dejaron en libertad (Expediente L-1, 80-57-73, F. 128, 15 de octubre de 1973).

Concepción, madre de los Corral García, recordó sobre ese hecho que: 
[... ] a raíz de cuando andaban buscando a Salvador y que se llevaron a Roberto, ya también Luis Miguel se movió de Juárez [...] El que estaba más separado del movimiento creo que era José de Jesús. Si sabría de ellos, pero pues él estaba en su trabajo aparte, pero como lo fueron a molestar allá. Yo creo que todo eso fue por causa de que Mónico los delató a todos [...] Sufrí mucho cuando andaban con eso y cuando se fueron porque yo sabía que se andaban exponiendo mucho a todo ese peligro (Entrevista a Concepción García, 25 de septiembre de 1997).

Sus tres hijos se fueron a la guerrilla. Salvador, al librarse de ser detenido en octubre de 1973, no regresó más a Ciudad Juárez. En los últimos meses de 1973, se trasladó a Culiacán, donde una mayoría de los militantes de la Liga en Sinaloa provenían de la fracción radical del movimiento estudiantil de principios de la década de los 1970. Desde entonces se les impuso el alias de “Los Enfermos”. A finales de 1973, sus dirigentes se encontraban presos o eran perseguidos. En parte por ello, los foráneos Héctor Escamilla Lira y Salvador Corral García se encargaron de un ensayo de huelga general, el Asalto al cielo, llevado a cabo el 16 de enero de 1974: los comandos guerrilleros urbanos y rurales de la LC23S coordinarían en el Valle de Culiacán la acción más grande planeada hasta entonces. El objetivo de este ensayo de insurrección civil era: “Educar a las masas en la acción armada, lanzar una ofensiva táctico-estratégica para desgastar al Estado burgués y foguear fuerzas para nuevas acciones" (CASTELLANOS, 2007, p.218).

Según la propia dirección nacional de la Liga, la participación de miles de jornaleros agrícolas fue espontánea, parando sus labores en los campos con exigencias de mejoras salariales. Aunque la Liga definió la jornada como exitosa -los diarios locales y nacionales la describieron como una situación caótica, un motín-, en un balance interior se señaló que las acciones no fueron encauzadas adecuadamente, ya que se desobedeció el plan original de entrar al centro de Culiacán, lo cual evitó incrementar el saldo rojo de tres militantes muertos y la detención de aproximadamente cuarenta. Horas después, la ciudad fue ocupada por militares y policías (CASTELLANOS, 2007, p.219; Comparecencia de Guadalupe Llanes Ocaña, 5 de marzo de 1975; Madera, 3, abril de 1974, 66). 


\section{La Liga Comunista 23 de Septiembre: entre la violencia política y la contrainsurgencia}

El 23 de enero de 1974, Salvador viajó de Culiacán a la Ciudad de México para entrevistarse con Ignacio Salas Obregón, líder máximo de la LC23S. Salvador, a través de éste último, entabló contacto con Ignacio Olivares Torres, miembro del Buró Político de la Dirección de la Liga y responsable en el estado de Jalisco. Olivares Torres nació en una familia de clase media originaria de Torreón, estudió la Licenciatura en Economía de la Universidad Autónoma de Nuevo León (UANL), donde fue presidente de la sociedad de alumnos, en 1967. Junto a su esposa, Hilda Dávila, viajó a Nueva York para cursar una maestría en la New School for Social Research, becado por la Organización de los Estados Americanos (OEA). Sin concluir los estudios de posgrado, regresó a Monterrey tras aceptar la secretaría académica de la Facultad de Economía. A principios de los 1970, debió elegir entre ser funcionario universitario o militante marxista, optó por lo último. Su fotografía se publicó en periódicos locales y nacionales al ser aprehendido junto con su esposa Hilda, vinculados con los asaltos bancarios de enero de 1972, en los cuales no participaron, pero eran parte de la organización responsable: Los Procesos. Salieron libres 48 horas después. El siguiente paso fue la clandestinidad combinada difícilmente con la paternidad. El Buró político de la Coordinadora Nacional de la LC23S lo nombró responsable del estado de Jalisco (Semanario Milenio, 2002, p. 36-40).

Después del frustrado intento de secuestro del industrial Garza Sada, se creía que la Liga se abstendría de realizar otra acción de este tipo, en parte debido a las exigencias de la iniciativa privada norteña de aplicar todo el peso de la ley y las medidas necesarias coercitivas -legales o no- para frenar lo que ellos observaban como la ola comunista y extranjera en nuestro país. Sin embargo, en menos de un mes, el 10 de octubre de 1973, comandos de la LC23S provenientes del Frente Estudiantil Revolucionario (FER), en la ciudad de Guadalajara, secuestraron al cónsul inglés Anthony Duncan y al empresario Fernando Aranguren. Exigieron como rescate 200 mil dólares y el traslado de 51 presos políticos hacia Corea del Norte, a través de la intermediación consular cubana. Algunos de los presos que integraban la lista y se encontraban recluidos en penales, como Lecumberri, Santa Marta y Chihuahua, rechazaron el secuestro y su incorporación a la lista 
de canje. Había conflictos internos entre militantes presos y libres. El procurador Pedro Ojeda Paullada rechazó cumplir con las condiciones de la LC23S a cambio de la libertad de los secuestrados. Como respuesta, los militantes liberaron al cónsul Duncan el 14 de octubre, Aranguren sería ejecutado tres días después.

La responsabilidad de la ejecución recayó en Olivares Torres, por ejercer la dirección de la LC23S en la localidad. Del caso se ha escrito abundantemente, señalando una serie de posibles responsables. Sin embargo, se ha proporcionado escasa información que facilite comprender las razones de la ejecución. En un comunicado firmado por el Comando Juanito del FER, se expuso a la opinión pública que el industrial trató de desarmar a un militante y por ello se le había ajusticiado, lo cual resulta un tanto inverosímil. Todo indica que fue una decisión de los integrantes provenientes del FER, rechazada por Olivares Torres. El homicidio del industrial ocasionó el traslado de Olivares Torres hacia Sinaloa en los últimos días de 1973, a donde viajó con su esposa, Hilda. Estando allá, fue llamado a participar en la reunión donde conoció a Salvador Corral. Ambos viajaron juntos de regreso del Distrito Federal hacia Sinaloa; Ignacio tenía como destino Mazatlán, Salvador se dirigía a Culiacán. No llegaron, el 30 de enero fueron detenidos en la carretera por la Policía Judicial Federal.

La familia de Salvador nunca supo del traslado de los dos jóvenes el mismo día de su detención a la sede de la DFS en la Ciudad de México, como lo informó el capitán Luis de la Barreda, entonces director de esta institución. En el interrogatorio también estuvo presente el jefe del Departamento Jurídico de la DFS, Julián Slim H., según consta en archivos depositados en el AGN (Semanario Proceso, 31 de diciembre de 2011), donde se encontraron a su vez las fichas de filiación de los dos detenidos, con fecha del 31 de enero de 1974 .

En ambas se observan las fotografías de Ignacio y Salvador, a blanco y negro, de frente y de perfil, con gestos adustos y miradas cansadas. Salvador llevaba el pelo crecido, largas patillas, bigote recortado y barba crecida. Su imagen es distinta a las fotografías que guarda la familia. Parecería que esta noche se convirtió en adulto, mayor a los 28 años que tenía al momento de ser detenido. La imagen de Ignacio, un año mayor 
que Salvador, da una impresión similar. En la parte inferior de los documentos se observan las huellas digitales de ambas manos.

En el caso de Salvador, Ilama la atención que al momento de declarar contestó dedicarse al comercio. Con ello pareciera que se incluyó con el resto de su familia, con la cual no convivía hacía por lo menos un año. Además, respondió tener como religión la fe católica, haber realizado el servicio militar, poseer un pasaporte, una credencial de elector, un registro federal de causantes, es decir, una vida pública y legal. En la ficha se inscribieron los motivos para su detención: “por encontrársele propaganda marxista”, tener como alias "Roberto", "David” y "Juan” y pertenecer a la Liga Comunista 23 de Septiembre. En el informe firmado por Luis de la Barreda, se señala que Salvador portaba un arma.

Por su parte, Ignacio Olivares señaló que no tenía ni ocupación ni domicilio fijo, así como aceptó ser parte del Buró Político de la LC23S. Supuestamente, en la declaración narró cómo y con quienes conformó dos comandos bajo sus órdenes, para secuestrar al cónsul Williams y al empresario Aranguren; y que al darse cuenta que no cumplirían con las condiciones que se exigieron para liberarlos, convocó a una reunión en la cual acordaron liberar al cónsul y retener a Aranguren, modificando las demandas. Sin embargo, señaló que después de la reunión Pedro Orozco (a) “Camilo” y Tomás Lizárraga (a) "El Tom de Analco", decidieron ejecutar al empresario "por burgués" (Expediente 11235- 74, Legajo 6, Foja. 35 a 42).

Dos días después, los cuerpos de Salvador e Ignacio fueron encontrados en colonias de Monterrey y Guadalajara, respectivamente.

\section{De la DFS a la prensa: Los rumores}

En los medios impresos, las noticias sobre las muertes de Corral y Olivares Torres se empezaron a publicitar como hallazgos de cuerpos sin identificar. En el archivo familiar de los Corral $^{6}$ se conserva una nota del Semanario Alarma, sin fecha, cuyo título es:

\footnotetext{
${ }^{6}$ Los familiares, como en otros casos, conformaron un archivo con las noticias sobre Salvador, la mayoría provenientes de la nota roja. Comúnmente, recortaron las noticias, quedando sin fecha y nombre de los
} 
“CRIMENES LLENOS DE CRUELDAD Y QUE SON VENGANZAS ENTRE GRUPOS DE EXTREMISTAS". La nota está acompañada de dos fotografías del cadáver de Salvador. En ella se hace referencia a un ajuste de cuentas, cuya prueba es la violencia visible ejercida en los cadáveres. "[...] es de suponerse que se trata de venganzas entre los componentes de los diferentes grupos de 'extremistas' que desde hace tiempo han venido formando problemas para el gobierno", declaró Carlos G. Solana Macías, jefe de la policía judicial del estado.

En cambio, Alerta de Guadalajara, sí identificó a Torres Olivares. La portada lleva como título: "MATAN AL CEREBRO DE LUCIO CABAÑAS", con la fotografía del cadáver de Ignacio, desnudo, con los ojos y la boca entreabiertos. En esta nota, es interesante destacar la relación que se establece entre Lucio Cabañas y Olivares Torres, éste como un ideólogo, el citadino estudiado, y el primero como uno de los escasos líderes guerrilleros campesinos reconocidos tanto por el Estado como por los medios. La alusión a Cabañas confirma además el ocultamiento de la LC23S como organización opositora y el uso de información falsa proporcionada por la DFS, cuyos agentes conocieron desde 1973 los conflictos y la imposibilidad de cooperación entre los militantes de la Liga y Cabañas.

En la misma nota, en un recuadro pequeño, se muestra una fotografía de perfil retratada cuando fue detenido en febrero de 1972. Además del título principal se leen otros enunciados: “Autor de los secuestros y la muerte de Aranguren”, "El cabecilla más buscado por todas las policías". Como pie de la fotografía del cadáver de Olivares, escribieron: “[... ] licenciado en Derecho, fue 'silenciado' por su propia gente a quienes en otro tiempo capitaneó. Golpes que le destrozaron [...]”. Con una biografía reconstruida y filtrada por la propia Dirección Federal de Seguridad, Jorge Pacheco Preciado, autor de la nota, lanzó la siguiente hipótesis: "fue víctima quizá por venganza o por el ajuste de cuentas entre sus mismos seguidores, quienes se autonombran guerrilleros". Al interior del semanario continúa la narración, donde se informó que las causas del fallecimiento de Olivares Torres fueron por "golpes en la cabeza que ocasionaron fractura en la base del cráneo e intensa hemorragia sanguínea por ambos oídos". La tesis de venganza o ajuste

diversos medios escritos. 
de cuentas se desprendía, según el autor de la nota, por las terribles condiciones en que se encontró el cadáver de Olivares Torres:

[...] en las piernas se le aprecian lesiones causadas con instrumento punzo cortante y contundente, lo que puede revelar que fue víctima de tormento o bien, que fue asesinado en forma brutal. La sentencia bíblica de que él que a hierro mata, a hierro muere, una vez más vuelve a cumplirse, pues está establecido que José Ignacio fue el autor del secuestro y posterior asesinato del rico industrial Fernando Aranguren Castiello y también el que planeó el plagio de los diplomáticos Terrance G. Leonhardy y Anthony Duncan Williams. El cadáver de José Ignacio fue localizado en el cruce de las calles de Metalurgia y Altos Hornos, colonia El Álamo. Tenía los pantalones de terlenka azul caídos hasta la rodilla; camisa color naranja con cuadros blancos, calcetines verdes y no llevaba zapatos (ALERTA Guadalajara, S.F).

A partir del 3 de febrero, los periódicos de Monterrey informaron del hallazgo del cuerpo de Salvador en la localidad y lo identificaron como probable responsable de la muerte de Garza Sada y sus guardaespaldas.

Identifican como uno de los asesinos de Don Eugenio al hombre que encontraron muerto... vendado, amordazado, atado y víctima de torturas, fue encontrado muerto en la colonia Fuentes del Valle, el sábado pasado. El occiso puede ser Salvador Corral García (a) Roberto, quien en compañía de Miguel Ángel Torres Enríquez (a) Ulises, Maximiano Madrigal Quintanilla “El boticario o Max, Edmundo Medina Flores (a) Héctor, Hilario Juárez García y los también muertos en acción, Javier Torres Rodríguez y Anselmo Herrera Chávez, perpetraron el fallido secuestro del industrial Don Eugenio Garza Sada, asesinando a este y a sus acompañantes Bernardo Chapa Pérez y Modesto Hernández, el 17 de septiembre anterior (TRIBUNA DE MONTERREY, S.F).

La comparación de notas de prensa con los informes elaborados desde la Dirección Federal de Seguridad nos permite identificar el modelo constante de filtración de datos que se publicaban posteriormente en las noticias. Como ejemplo, el capitán Luis de la Barreda escribió el 4 de febrero sobre el reconocimiento del cadáver de Salvador Corral por algunos presos en el penal de Topo Chico: 
Dirección Federal de Seguridad, Estado de Nuevo León. Gustavo Hirales dijo no reconocer a esa persona. Mónico Rentería manifestó encontrarle parecido con Salvador Corral García. Elías Orozco expresó que probablemente se tratara de Salvador (a) Roberto, al que tenía aproximadamente año y medio de no ver.

El día 7 de febrero se publicó:

Hallaron asesinados a dos guerrilleros. Identificó la policía el cadáver de un extremista en Monterrey. La policía judicial identificó el cadáver, encontrado en la aristócrata zona de Fuentes del Valle, como el de Salvador Corral García, uno de los individuos más buscados por el norte de la República. Por medio de retratos hablados que fueron presentados a varios terroristas encarcelados en el penal del Estado. Dichos terroristas que identificaron al hoy occiso como Salvador Corral García son: Adolfo Hirales Morán, participante en varios atracos bancarios. Mónico Rentería, autor intelectual de los atracos y participante directo en el fallido secuestro del industrial Eugenio Garza Sada; Elías Orozco Salazar autor de la muerte del industrial (La Prensa, 7 de febrero de 1972).

Tanto el informe de la DFS como la nota muestran una relación entre la prensa y el Estado mexicano denominada por Gamiño como una celebración de pactos de lealtad, no firmados pero consensuados por gobernantes y empresarios, donde algunos medios escritos promovieron "juicios denotativos; ejerció un carácter informativo desde una perspectiva policial; ponderó el amarillismo y, en todo momento, justificó la represión" (GAMIÑO, 2011, p.130).

\section{La desconfianza}

Con el objetivo de debilitar y quebrantar los compromisos de silencio que impedían la obtención de información sobre la estructura de la organización, localización de brigadas, identificación de personas, se fomentó la desconfianza como estrategia de fragmentación. En el caso de Olivares Torres y Corral García, el propósito fue diagnosticar entre los militantes el grado de credibilidad sobre la versión de un posible ajuste de cuentas interno. Gustavo Hirales recuerda que hasta Topo Chico llegaban los de la DFS preguntando: “¿Quién creen que lo haya matado? ¿Creen que haya sido un ajuste de cuentas interno o sería la familia Garza Sada?". Hirales señala que él y sus compañeros 
presos no dudaron de la responsabilidad del Estado, aunque no conocían los detalles de la detención, "después quedó muy claro que fueron ellos, con las comunicaciones de la DFS ¿No?”. La confirmación de la responsabilidad estatal llegó hasta el año 2002 (GUSTAVO, 2012).

Un ejemplo de la generalización de esta práctica por parte de las fuerzas de seguridad del Estado son los homicidios de Joel Rojo Hernández, bibliotecario de la Universidad Autónoma de Nuevo León, y de Rodolfo Garza Montemayor, del Sindicato de Trabajadores de esta misma universidad, quienes, según las noticias, habrían sido ajusticiados en situación similar que Salvador, es decir, por sus propios compañeros. Sin embargo, ni Rojo Hernández ni Garza Montemayor eran integrantes de la LC23S.

El 10 de febrero de 1974, a una semana de encontrarse el cadáver de Corral García en Monterrey, los comités revolucionarios estudiantil y obrero elaboraron y difundieron un documento dirigido a la clase obrera, en el que distinguían dos clases de violencia: la reaccionaria, ejercida por parte de la burguesía y el Estado, y la revolucionaria, de las masas explotadas. Los militantes regios expusieron:

La prensa nacional y en particular la local, intenta igualar actos de violencia que son cualitativamente distintos, contradictorios y antagónicos. Quieren hacer aparecer los asesinatos de los dirigentes revolucionarios José Ignacio Olivares Torres (a) "Sebastián" y Salvador Corral García (a) "Roberto", iguales a las eliminaciones de los policías políticos Antonio Joel Rojo Hernández y Rodolfo Garza Montemayor. Los primeros son actos de violencia reaccionaria y los segundos de violencia Revolucionaria (Expediente 11-235- 74, Legajo 6, Foja. 176 a 182).

En el documento de seis hojas, argumentaron la diferencia entre las violencias y asumieron la eliminación de dos supuestos policías políticos. Descartaron dar explicaciones, ya que en Monterrey "afortunadamente, eran bien conocidos como traidores a los intereses del proletariado y además como policías políticos”. Por ello, su eliminación sería una táctica para desgastar y desarticular a la policía política. Sobre la participación de Rojo y Garza en labores de policía política, no encontramos fuentes historiográficas ni primarias, con excepción del documento citado anteriormente y unas escuetas declaraciones de Héctor Escamilla frente a la prensa de Monterrey el 27 de abril 
de 1974, en las cuales respondió que Jesús Piedra Ibarra (a) "Rafael”, le informó que “Rodolfo Garza Montemayor (a) 'el Perro' y Antonio Joel Rojo Hernández (a) ‘Rojo', muertos el 3 de febrero y el 17 de enero de este año, fueron asesinados por ser policías políticos" (Expediente 11-235-74, L-11, Foja. 142).

Los homicidios de Garza Montemayor y Rojo Hernández se produjeron dentro una denominada lucha contra el oportunismo y la unión a toda costa, ya que "no sería posible avanzar con el movimiento revolucionario sin deslindar campos, es decir, aislar a los oportunistas de los verdaderos revolucionarios". Las razones expuestas para esta purga fueron la poca o nula teorización a través del marxismo, las desviaciones y vicios de las militancias anteriores, los intentos de vinculación con otras fuerzas políticas reformistas, entre otros argumentos (Madera, mayo de 1974). Ante la diversidad de origen de los diferentes grupos que integraron la LC23S, podemos suponer la heterogeneidad de sus integrantes, así como la posibilidad de que algunos de ellos continuaran con relaciones personales surgidas en militancias anteriores.

Durante las entrevistas, es interesante observar cómo reaccionan los sobrevivientes cuando se les pregunta sobre estas acusaciones, mayoritariamente en contra de líderes de la izquierda estudiantil, sindical o campesina que no participaron de la militancia de la LC23S. Regularmente, responden que aquellas amenazas no pensaban en llevarlas a cabo. Por su parte, algunos de los amenazados confesaron su confianza en el respeto, cariño o compañerismo previos a la etapa de radicalización que evitaron una agresión hacia su persona (Entrevista a Miguel, abril de 2011; Comunicación con Jaime García Chávez, marzo de 2012). No sucedió lo mismo con Garza Montemayor y Rojo Hernández. ${ }^{7}$ La confianza en los otros se desgastó. El espectro del enemigo rebasó el margen de las instituciones estatales. A la etapa de fundación le prosiguió un período de deslindes y desconfianzas.

\footnotetext{
7 Rodolfo Garza Montemayor era miembro del Sindicato de Trabajadores de la Universidad Autónoma de Nuevo León, cercano al líder sindical Fabián Navarro. El 15 de julio de 1972, fueron detenidos con otros sindicalistas por alumnos de la Facultad de mecánica y eléctrica que mantenían la toma de rectoría al creer que acudían para tratar de desalojarlos. Esta ocasión, Garza Montemayor fue golpeado hasta confesar por escrito que el entonces rector Héctor Ulises no contaba con la mayoría necesaria dentro de la junta de gobierno universitaria. Véase: FLORES, Oscar (S.F).
} 
"Yo ya me voy a morir a los desiertos..."

Era la mañana del 2 de febrero de 1974 en Ciudad Juárez, Chihuahua. Don Telésforo Corral se encontraba desayunando, mientras su esposa Concepción atendía el negocio "La Industrial”, refaccionaria de Roberto. Concepción avisó a Roberto: "ahí te hablan los que te llevaron el otro día". Estos le anunciaron:

¿Sabes qué? Ya encontramos a tu hermano. Lo encontraron en Monterrey, en una colonia de las más populosas. Lo encontraron tirado, quizás sus mismos compañeros lo han de haber asesinado. Pero venimos a avisarles, si ustedes quieren irlo a recoger para avisar nosotros allá. (ROBERTO, 2009).

En el plano familiar de los Corral García, la muerte de Salvador fue el primer episodio violento que vivieron, un desenlace que según los hermanos y las hermanas preveían podría ocurrir de un día a otro, pues sabían en lo que andaba. Pareciera que la familia vislumbró dos bandos antagónicos: el del hermano y el de las fuerzas contrainsurgentes. Ellos, como familia, no pertenecían a ninguno de los dos.

Roberto recuerda que lo invadió una sensación de temor al trasladarse en automóvil hacia Monterrey por el cuerpo de Salvador. Estaba seguro que encontraría a los policías que lo detuvieron. Al llegar a la funeraria, se encontró con ellos. Roberto se atrevió a preguntar:

¿Ya qué quieren, qué le piden? ¿Ya para dónde se va? No, me dijeron, aunque no lo creas estamos nosotros acá esperando al señor Palma, que lo mataron en Sinaloa por los mismos motivos. Era uno de la ley que habían matado por allá. Nos tocó en la misma funeraria. Ya con eso nadie estaba tranquilo. (ROBERTO, 2009).

Roberto recuerda perfectamente el momento en que reconocieron el cuerpo de Salvador, "tenía quebrada la mandíbula con unas pinzas, los dientes, los brazos, incluso cuando fui lo sacaron arrastrando así de un pie por el piso. Lo aventaron así: ¿Ese es? Se siente uno así, impotente, con coraje”.

\footnotetext{
${ }^{8}$ Canción popular cardenche de una región entre los estados de Durango y Coahuila.
} 
Roberto también recuerda que en un viaje anterior a Monterrey conoció a un comerciante de nombre Francisco Pérez, al que nunca volvió a ver hasta este febrero de 1974, que llegó atraído por las noticias:

\begin{abstract}
Ese señor se presentó con nosotros y nos dijo: quiero que me hagan el favor de aceptarme este traje para Salvador. Aparte de eso nos dijo: esperen en la troca a la salida de la funeraria, yo me encargo, porque ahorita se viene la prensa, se va a poner así (Hace una expresión con la mano que significa una gran cantidad). Ya no lo volví a ver, no sé si vive todavía, pero ese detalle él lo hizo, nunca se me va a olvidar. (ROBERTO, 2009).
\end{abstract}

En el acta de defunción, expedida por el Registro del Estado Civil del estado de Nuevo León, se asienta que Salvador falleció de un shock traumático secundario a fractura de cráneo encefálico producido en la trayectoria de proyectil de arma de fuego. Por parte de la familia, no se interpuso una denuncia por la ejecución de Salvador y de oficio tampoco se siguió una investigación. ${ }^{9}$

Roberto recuerda que inmediatamente se trasladaron a Ciudad Juárez: "Teníamos que ir a preparar su funeral allá en Juárez. Hablamos, dijimos que se preparara la gente porque no queríamos tenerlo mucho velándolo, nomás por lo mismo, llegamos a las 3 y a las 5 lo sepultamos". Cuando llegó el cuerpo de Salvador a Ciudad Juárez, alguien de la familia lo fotografió. No lo habían visto por más de un año. Fue sepultado el 7 de febrero. Al otro día, en la prensa local se informó del homicidio con la misma hipótesis de un ajuste de cuentas al interior de la guerrilla.

Ciudad Juárez está congestionada de guerrilleros. Los hay en un crecido número y no porque aquí busquen refugio o se reúnan para planear sus golpes, sino porque esos guerrilleros o extremistas como se les ha dado en llamar son de Ciudad Juárez. Aquí nacieron, aquí estudiaron, aquí tienen sus novias, sus esposas o sus padres y hasta se cree que aquí recibieron la instrucción que los convirtió en rebeldes. Ayer a las 5 de la tarde en el panteón Tepeyac, había de menos 12 de los más activos guerrilleros que operan en todo el país y que los que no eran de aquí vinieron expresamente para asistir al funeral de Salvador García Corral

\footnotetext{
9 En el 2002, cuando Concepción García denunció la ejecución de Salvador ante la Fiscalía Especial para Movimientos Sociales y Políticos del Pasado, no se encontró expediente alguno en los archivos de la Procuraduría de Justicia de Nuevo León.
} 
(sic). Hacía como dos años que no veíamos a Salvador. Éste estudió en esta ciudad hasta terminar la secundaria y la preparatoria. Se fue a la Capital de México y cuando estaba a punto de recibirse de doctor, interrumpió sus estudios para unirse a un grupo de jóvenes, casi todos ellos profesionistas que decían que se iban a lanzar a la lucha para acabar con las injusticias que se estaban cometiendo contra el pueblo mexicano. Jóvenes que aquí trataron a Salvador, dicen que éste, cuando menos en la frontera, no era cabeza de ningún grupo. Estudiantes de la preparatoria del Parque, de la secundaria nocturna y de la normal de esta frontera, formaban los grupos pero por lo general los dirigían personas que venían de otros puntos (EL MEXICANO, 8 de febrero de 1974).

Esta nota da la sensación que fue redactada con un exceso de imaginación por parte de su autor, Apolinar Ochoa, al anunciar la presencia de doce guerrilleros en los funerales. Pero en las pláticas con los familiares de militantes que murieron, es común que se recuerde la presencia policiaca para registrar los asistentes a los velorios. Aunque en la nota se utilice adjetivos como extremistas que se reúnen para planear sus golpes, con una condena implícita de ilegalidad, llama la atención la manera en que se identifica a Salvador como un joven juarense, de un pasado inmediato sin antecedentes penales, como muestra de una vida decente, cuyo destino se modificó tras recibir "una instrucción para convertirse en rebelde". Todas, presunciones del autor por entrevistas que realizó como lo señala en su nota- tanto a compañeros de estudios de Salvador como a Roberto Corral, ésta última vía teléfono. Quien escribió la noticia, más allá de informar sobre una reunión de extremistas en un panteón fronterizo, trató de explicar por qué alguien con relaciones familiares, escolares, amistosas, abandonó su vida legal para irse de guerrillero.

\section{Conclusiones}

En este artículo, se ha intentado analizar, a través del caso Corral y Olivares, aquellas formas por medio de las cuáles una generación de jóvenes creyó que podría llegar a hacer posible una revolución socialista en el México de los 1970. Los jóvenes recién organizados en la LC23S pretendieron hostigar a la burguesía nacional a través del secuestro de dos de sus integrantes para el pago de un rescate como tributo de guerra, además de obligar al Estado mexicano a negociar la liberación de presos políticos. Con ello, lograrían visibilidad ante a la opinión pública, pero sobre todo, ante los trabajadores 
y las trabajadoras con el propósito de que conocieran de su existencia y del proyecto revolucionario, y en un momento dado, se integraran al ejército proletario.

Sin embargo, tras los secuestros del cónsul inglés Duncan Williams y de los empresarios Garza Sada y Aranguren Castiello, así como de los homicidios de los dos últimos, se observaron las profundas diferencias entre los grupos empresariales especialmente el del norte- y el gobierno federal, los cuales habían sido considerados como aliados y semejantes por los jóvenes revolucionarios. El impacto mediático desplegado por las cámaras empresariales, que condenaron y exigieron acciones legales e ilegales en contra de los jóvenes rebeldes, propició una oleada de solidaridad con las familias de los empresarios, así como la inmediata acción contrainsurgente, en cabeza del entonces presidente Echeverría.

En el texto, es reconocible que si bien nos ocupamos de los primeros meses de vida de la LC23S, la DFS contaba por lo menos con dos décadas funcionando como agencia investigadora de movimientos opositores. Por otro lado, pareciera que las investigaciones a las decenas de grupos surgidos en los 1970 los tomó por sorpresa, aunque en algunas investigaciones recientes basadas en los expedientes de la DFS se otorgue un papel destacado y exitoso a la supuesta infiltración en las organizaciones armadas -en el caso de Garza Sada se le ha dado especial protagonismo-. Con base en estos expedientes nos atrevemos a plantear que las actividades de espionaje, seguimiento, detención, tortura y ejecución de opositores políticos fueron realizadas por una estructura varonil, vertical, dirigida por personajes relacionados con altos mandos gubernamentales, incluidos militares, con los cuales establecieron profundas relaciones de lealtad. Una gran parte de sus agentes -contratados por recomendaciones y redes de compadrazgos- no realizaron estudios profesionales, lo cual limitó su capacidad de analizar la información de los detenidos obtenida por tortura en la mayoría de los casos.

Respecto a la oposición política, los cuerpos de seguridad obtenían la cooperación de instituciones locales y estatales, como ocurrió en el caso de Garza Sada, en el cual participó la policía judicial de Nuevo León, y hay indicios de la también vinculación de la seguridad privada de la Cervecería Cuauhtémoc, no obstante, hasta hoy se desconoce públicamente si formaron parte de las investigaciones y si, en determinado momento, 

tribunales a quienes no participaron en el homicidio de Garza Sada, como fue el caso de Mónico Rentería, así como detener y ejecutar a Salvador Corral García e Ignacio Olivares Torres, a manera de mensaje simbólico dirigido tanto a los grupos guerrilleros como a los grupos empresariales. Creemos que los liderazgos regionales de Salvador Corral y de Ignacio Olivares los convirtieron en blanco para responsabilizarlos de las muertes del octogenario norteño y del joven Aranguren. Estos errores y determinaciones, como les Ilamaron a las causas asumidas desde la LC23S, también fueron interpretados por la DFS como crímenes colectivos del bando enemigo. Por ello, a través de las terribles torturas y ejecuciones de Corral y Olivares, castigaban a la organización.

El combate a las organizaciones insurgentes de los 1970 contó con la cooperación de las empresas de la comunicación. Las cuáles, señala Gamiño, tendieron a "auxiliar al Estado para mostrar al movimiento armado como un fenómeno delincuencial atípico en la historia del país" (GAMIÑO, 2011, 130). En el texto intentamos ilustrar un modelo en que las pesquisas de la DFS, filtradas inmediatamente, se publicaron de manera casi idéntica como noticias en diversos medios esparciendo versiones a manera de rumor. La escena o el montaje en el que fueron expuestos públicamente los cadáveres, tanto en Monterrey como en Guadalajara, mostró las formas en que serían combatidos los militantes de la LC23S. La hipótesis creada por las instituciones gubernamentales y los medios de comunicación sobre Corral y Olivares señalaba un ajuste de cuentas interno entre los militantes de la LC23S. Se mataban entre ellos, concluyeron.

Al margen de las narraciones de sobrevivientes y familiares sobre la violencia ejercida por los cuerpos contrainsurgentes contra militantes de la LC23S, aparece la arista incómoda de las ejecuciones de Rodolfo Garza Montemayor y Antonio Joel Rojo Hernández, en el contexto de la cruzada en contra del oportunismo emprendido por la LC23S. El silencio alrededor de este hecho evidencia un conflicto memorístico y de justicia ocasionado por la falta de explicaciones de los entonces militantes. Estas omisiones o silencios muestran la dificultad de analizar críticamente la militancia radical. Queda 
pendiente historiar estos pasajes rojos que permitan cubrir las lagunas de lo inexplicable. Con ello tal vez podría realizar un ejercicio comparativo, entre las diferencias de métodos tanto del Estado mexicano como de los jóvenes rebeldes de los 1970, dando con ello mayor sentido al proceso armado que emprendieron estos últimos con expectativas de transformación.

\section{Referencias}

\section{Documentos DFS}

Comparecencia de Guadalupe Llanes (sic) Ocaña ante el Ministerio Público. CuliacánSinaloa., Marzo 5 de 1974.

Expediente 11-235- 74, Legajo 6, Fol. 35 a la 42.

Expediente clasificado sobre Salvador Corral 11-235-73, octubre de 1973.

Expediente L-1, 80-57-73, Fol. 128. Informe del capitán Luis de la Barreda Moreno. Octubre 15 de 1973.

Expediente 11-235- 74, Legajo 6, Foja. 176 a 182.

Expediente 11-235-74, L-11, Fol.142.

\section{Orales}

Comunicación de Alicia de los Ríos \& Jaime García Chávez. Chihuahua, marzo de 2012.

Concepción García Viuda de Corral: entrevista de Jesús Vargas Valdés. Ciudad Juárez, Chihuahua, septiembre 25 de 1997.

Gustavo Hirales Morán: entrevista por Alicia de los Ríos Merino, Ciudad de México, septiembre 25 de 2012.

Miguel: entrevista por Alicia de los Ríos Merino, Ciudad Juárez, abril del 2011.

Rigoberto Ávila: entrevista por Alicia de los Ríos Merino, Ciudad de México, 7 de noviembre de 2009. 
Roberto Corral García: entrevista por Alicia de los Ríos Merino, Ciudad Juárez, agosto del 2009.

\section{Electrónicas}

FLORES, Oscar. Monterrey 1910-1980. Desarrollo urbano de la ciudad de Monterrey México en el siglo XX. Disponible en: <http://issuu.com/oflores/docs/monterrey_19101980_de_oscar_flores_tii/213>. Acceso en: 12 de enero de 2014.

GAMIÑO, Rodolfo. Prensa oficialista y acción guerrillera en la década de 1970: el caso de la Liga Comunista 23 de Septiembre, In: Antropología. Boletín Oficial del Instituto de Antropología e Historia, núm. 94, INAH, México DF, 2012. Disponible en: <http://www.revistas.inah.gob.mx/index.php/antropologia/article/view/2704/2607>. Acceso en: 6 de enero de 2015.

SALDAÑA, Manuel: entrevista a Diego Enrique Osorno, La familia Garza sabía del atentado 2002, publicada en El Barrio Antiguo, Monterrey, 15 de septiembre de 2013. Disponible en: <http://www.elbarrioantiguo.com/la-familia-garza-sada-sabia-del-atentado/>. Acceso en: 3 de julio de 2015 .

\section{Hemerográficas}

Alerta de Guadalajara. Matan al cerebro de Lucio Cabañas. Sin Fecha. (Archivo familiar).

Tribuna de Monterrey. Febrero de 1974. (Archivo familiar).

El mexicano. Lo mataron en Monterrey, Nuevo León. Sepultaron a extremista. Por: Apolinar Ochoa, febrero de 1974 (Archivo familiar).

Madera. Huelga independiente en las mazmorras de la burguesía en Sinaloa núm. 3, Abr.1974 (Archivo familiar).

Madera. La Tercera Reunión Nacional y las nuevas aportaciones a la "teoría de la vinculación partidaria". Madera, periódico clandestino. Núm. 4, mayo de 1974 (Archivo familiar).

Semanario Alarma. Crímenes llenos de crueldad y que son venganzas entre grupos de extremistas, sin fecha (Archivo familiar).

Semanario Milenio. La ejecución de Sebas. Por: Fritz, Darío. núm. 264, octubre 7 de 2002.

Semanario Proceso. El “olvidado” comandante Slim Helú. núm. 1835, diciembre 31 de 2011. 


\section{Impresas}

CASTELLANOS, Laura. México Armado. 1943-1981. México: Ediciones Era. 2007. México.

CERUTTI, Mario. Propietarios, empresarios y empresa en el norte de México: Monterrey: de 1848 a la globalización. Editorial Siglo XXI. 2000.

GAMIÑO, Rodolfo. Guerrilla, represión y prensa en la década de los setenta en México. Invisibilidad y olvido. México: Instituto de investigaciones Dr. José María Luis Mora. 2011.

HOLGUIN, Jorge \& REYES, Miguel. La insurgencia urbana en Colombia: accionar colectivo del M-19 en Cali, 1974-1985. Universidad del Valle-Departamento de Historia. Colección Historia y Espacio (En prensa). 